Reprod Health Matters. 2003;11(21): 161-70. Doi: 10.1016/S09688080(03)02164-5.

13. Malena C, Forster R, Singh J. Social accountability: An introduction to the concept and emerging practice. Social Development Paper No. 76. Washington, DC: World Bank; 2004.

14. Schaaf M, Dasgupta J. "Our fear is finished," but nothing changes: efforts of marginalized women to foment state accountability for maternal health care in a context of low state capacity. BMC Public Health. 2019;19,:732. https://doi.org/10.1186/s12889-019-7028-2.

15. Boydell V, Schaaf M, George A, Brinkerhoff DW, Van Belle S, Khosla R. Building a transformative agenda for accountability in SRHR: lessons learned from SRHR and accountability literatures. Sex Reprod Health Matters. 2019; 27(2):64-75. Doi: 10.1080/26410397.2019.1622357

\title{
Examining women's health through a psychosocial lens
}

\author{
SATHYASREE GOSWAMI
}

\begin{abstract}
During the COPASAH Global Symposium 2019, a group of therapists and mental health practitioners tried to highlight the issue of women's mental health with two specific focuses, one being the lived experiences of persons living with mental illness and the secondary burn-out and shame faced by their caretakers. The second session explored the contours of somatisation that is often seen in the human body as a result of the impact of trauma. The participants reflected on the value of lived experiences and also discussed the challenges faced in getting representation for people living with mental illness. The challenges listed by participants were concentrated around the participation and representation of persons living with intellectual disability and psychosocial disability. Somatisation of traumatic experiences needs recognition in a country like India where women's life-stressors exist right from childhood that keeps them on the threshold of mental illness and/or psychosomatic illnesses. Psychosocial health issues are relegated to a subordinate category of discussion while public health, reproductive health, and health rights feature in mainstream discussions in various seminars, researches and conferences in India. This paper is based on two sessions of the COPASAH Global Symposium 2019 and focuses on the gender and psychosocial dimensions of health from the framework of women being subjected to unpaid care work, through social and reproductive labour and stressors resulting in psycho-social
\end{abstract}

Author: Sathyasree Goswami (g.sathyasree@gmail.com), Doctoral Scholar, Tata Institute of Social Sciences, Deonar, Mumbai, INDIA.

To cite: Goswami S. Examining women's health through a psychosocial lens. Indian J Med Ethics. 2021 Oct-Dec; 6(4) NS: 290-93. DOI: 10.20529/IJME. 2021.077

Manuscript Editor: Sunita VS Bandewar

Peer Reviewers: Sadhana Natu

(c) Indian Journal of Medical Ethics 2021 distress. To this end, it is important to build a community of practitioners that looks beyond the reproductive health of women.

Keywords: Women's health, somatisation, psycho-social wellbeing

\section{Introduction}

It is still taboo in India to seek support for mental health distress. A nationwide survey on mental illness in India estimated that about 150 million adults over the age of 18 years are in need of mental healthcare (1). As the Sustainable Development Goals (SDGs) have generically clubbed mental illness under non-communicable diseases and substance abuse (2), attention needs to be focused on the need to consider the sociopolitical-cultural contexts of people with psychosocial disabilities. Women with psychosocial disabilities (PSD) face greater vulnerability and are subjected to increased stigma and discrimination. Additionally, it is also transpersons, poor women, female sex workers, and queer women, who face greater barriers in the exercise of their political and civil rights.

According to the World Health Organization (WHO) (3), gender differences are seen in the prevalence rates of common mental disorders like depression, anxiety and somatic complaints. It is understood that women predominate in numbers in common mental disorders and this is considered to constitute a serious public health problem. However, little or no focus is seen on transpersons, poor women, female sex workers, queer women's PSD issues. In the practitioner's huddle during the symposium, a participatory session outlined the importance of listening to people with lived experience of PSD and engaging with them in community-based prevention and therapy practices.

The Symposium also had a session to understand the somatic $^{1}$ repercussions of stress and trauma, especially those 
to which women are subjected. One major stressor is unpaid care work that is most common but always overlooked. The annual study of wealth inequality worldwide released by Oxfam in the run up to the Davos World Economic Forum points out that in India, unpaid work done by women looking after their homes and children amounts to 3.1 per cent of the country's GDP (4). The report further adds that in comparison to men who spend only 29 minutes in urban areas and 32 minutes in rural areas on unpaid care work, women spend 312 minutes per day in urban areas and 291 minutes per day in rural areas in such work. It is no surprise then that studies show the prevalence rates of many musculoskeletal pain conditions to be higher among women than men, as these are associated with higher levels of disability and psychological distress than having a single pain condition (5). In spite of knowing this, we have not yet been able to correlate the relationship between women's physical pain and the burden of unpaid care work.

Psychosocial health issues are relegated to a subordinate category for discussion while public health, reproductive health and health rights are in the mainstream discussions in various seminars, researches and conferences in India. This paper is based on two sessions of the COPASAH Global Symposium 2019, and focusses on gender and psychosocial dimensions of health from the perspective of women being subjected to unpaid care work through social and reproductive labour, and their specific life stressors that result in psychosocial distress.

\section{Psychosocial health and care giving}

During the COPASAH Global Symposium 2019, a group of therapists and mental health practitioners tried to highlight the issue of women's mental health with two specific focuses, one the lived experiences of persons with mental illness and the secondary burn-out and shame faced by their caretakers. The other session explored the contours of somatisation that is often seen in the human body as a result of trauma. The former session was co-facilitated by the author with Dr Kaaren Mathias, a public health physician working in Uttarakhand state of India.

A short film ${ }^{2}$ made by the Emmanuel Hospital Association (EHA) showed how a toolkit that was developed jointly with people with lived experiences (PWLE) of mental health problems was effective in its implementation through a participatory approach. The participants reflected on the value of lived experiences and also discussed the challenges in getting representation for people living with mental health problems. The challenges that participants listed centre especially on participation and representation of persons living with intellectual and psychosocial disability. Some participants shared actual examples of positive input in the implementation of community-based rehabilitation of psychosocial disability, along with the challenges for participation. Most often, the agency of persons living with a psychosocial illness is taken for granted, however this session was extremely helpful in understanding this concept of "agency". The value of partic-ipatory mechanisms in community-based implementation of mental health programmes was emphasised and the inclusion of such examples in policy was recognised.

\section{Somatisation and psychosocial health}

Another session in the Symposium focused on mental health, especially that of women and also dealt with how the body holds (internalises) trauma which is further manifested as varied disabilities. This session was a special performance-based discussion on somatisation and "wellbeing" primarily facilitated by Anitha Santhanam from Guduguduppukkari, Bengaluru, and co-facilitated by the author. The performance focused on the need to delve into the wisdom of the body, how that is possible for us, and whether we allow the body to communicate with us or let the mind take over; this was performed by Anitha Santhanam. The discussion was on how various societal norms govern the lives of women, be it through control of the body or the expected role to be performed by the body.

The social framework that validates a woman's existence is primarily through the body. The ability to do care work and bear children, the emphasis on physical appearance in traditional notions of beauty, and her bodily subjugation to the ownership of men, are the essentials of this framework. Studies in the global North show that although women suffer more physical pain compared to men, the paradox is that women's pain reports are taken less seriously (6). Methods of controlling and assisting women's reproduction by manipulating their bodies are the common practice of the public health system in India. The overt focus on women's reproductive and maternal (and child) health further brings the body under the control of the State and patriarchal forces. However, the increased burden on women in intersecting groups like those in sex-work, transpersons, queer women, Dalit women, Muslim women, needs deeper study and the fact that these sessions were unable to explore it was a limitation.

\section{Aches, pains and shame}

The discussion that followed the performance in this session focused on various aches, pains, burning sensations, that women face, and the shame associated with their physical body that is so often overlooked. Somatisation of traumatic experiences needs recognition in countries like India where women's life-stressors exist right from childhood, placing them on the threshold of mental illness and/or psychosomatic illnesses. The second leading cause of global disability by 2020 was predicted to be unipolar depression, which is twice as common in women. Further research is needed to confirm that depression is not only the most common women's mental health problem but may be more persistent in women than in men, as stated by the WHO (3).

Domestic violence, sexual violence, and emotional violence 
at the workplace all need to be considered while understanding how a woman sees her own body and how this could relate to diseases like chronic pain. Therefore, while dealing with women's health and well-being, it is imperative to holistically understand a woman's physical and psychosocial wellbeing, keeping various factors in mind. Since the focus on non-reproductive health of women is so inadequate, and hence neglected, it is important to understand bodily pain from a trauma-informed standpoint (7). However there are very few studies in India that correlate these factors to understanding women's overall health and wellbeing.

\section{Exposure to violence}

It has been understood that most often families are the sites of sexual violence against girls, boys and women, combined with physical violence, and it is in this family space that the perpetrators often lurk and are provided shelter. In a recent work on masculine norms and violence, the authors talk about how the hegemonic order of masculinity "contributes to an inequitable and oppressive distribution of status and power, often policed and patrolled by state-sanctioned violence" (8). Significantly, it has been found that women exposed to physical or sexual violence were more likely to report somatic symptoms. Globally, intimate partner violence (IPV), also significantly high amongst female sex workers, is considered a major global public health problem (9). Exposure to violence has been shown to have an impact on somatic health. Although very few studies are conducted in India around somatisation, it is understood from studies conducted in the West that violence has been associated with the presence of somatic symptoms and diseases. They reiterate that complaints such as stomach pain, back pain, pain in arms/legs/joints, menstrual pain/problems, pain/ problems during sexual inter-course, headache, chest pain, dizziness, fainting spells, feeling your heart pound or race, shortness of breath, constipation/loose bowels/diarrhoea, feeling tired/ having low energy, and trouble sleeping, are somatic symptoms. These symptoms increase or are intensified when a woman is exposed to more and more violence (10). Although practitioners understand the presence of violence in the lives of queer women, sex workers and transpersons, specific studies are rarely found.

In a country like India where almost every woman has experiences of childhood sexual abuse with differing degrees of intensity and duration, it is not uncommon for somatisation to occur. Further, drunkenness and alcohol misuse by the male partner are associated with poor mental health and spousal violence among married women and female sex workers in India. This is corroborated by a study conducted in Goa, where women's attitudes condoning male spousal violence were independently associated with mental health problems in women. This was a population study on alcohol use patterns and sexual risk behaviours conducted in rural and urban areas of North Goa, with women aged 18-49 years (11).

\section{Beyond reproductive health}

While it is recognised by the United Nations Population Fund (UNFPA) that gender equity is a human right (12), the focus on women's health issues is dominated by reproductive health and/or sexual and reproductive health. Simultaneously, the fact that UNFPA does not mention nonbinary gender persons, and only mentions women, shows how gender equity excludes the perspective of queer women and transpersons. While maternal health is important, other health issues faced by women are neglected. As mentioned earlier, WHO estimated (3) depression to be the second largest contributor to disease burden by 2020; specifically predicting that one in every three women worldwide would be afflicted by common mental disorders including depression. While antenatal services, maternal healthcare and safe deliveries are the right of every woman, the cost of reproductive labour and unpaid care work impose a burden on their bodies' nonreproductive functions as well.

Stigma and shame associated with a woman seeking her own well-being is so deep rooted, that even educated women in India are unable to understand that living in stressful conditions of physical/psychological (domestic) violence or having a traumatic history from childhood could make them susceptible to post traumatic stress disorders. As feminist theorists have argued, women's wellbeing is not solely determined by biological factors and reproduction, but also by the effects of heavy workload, poor nutrition, stress, war and migration (13). It is important to examine the interrelations of such factors. Links between economic hardship, child death, emotional deprivation, and psychological distress in women have also been documented in many anthropological studies (14).

\section{Building community solidarity}

The Global Symposium provided a space to open up an often understudied and undiscussed issue of women's health and wellbeing. Although these two sessions focused on cis-women, there were other sessions where intersectionality and gender equity were discussed. Interestingly, in a study conducted to understand how women perceived their illness and weakness, it was found that women attribute it to poverty, overwork, not enough food, neglect and increased violence, resulting in poor physical and mental health conditions (15). Trivialisation of women's experiences of physical pain is also internalised, as women consider talking about their pain as a stigma (16). The EHA intervention shows that a participatory approach is extremely effective in dealing with community coresponsibility in specific reference to PWLE. It could perhaps be understood that society values a woman who is productive both by bearing children and doing unpaid care work. Hence, it is worthwhile to examine whether acknowledging women's illness would require changes in gender roles that might be threatening to the larger society. 
As a community of practitioners and researchers, collective action would certainly enhance the focus on this issue.

\section{The way forward}

Studies are needed that engage deeply with various determinants of health from a gendered perspective, which would enhance the understanding of the interconnectedness of women's overall health and wellbeing to life stressors. Towards this end, it is important to build a community of practitioners that looks beyond the reproductive health of women.

Further, exploring the issue of women's psychosocial health through the lens of intersectionality would deepen this understanding both in research and practice. The discrimination faced by transpersons, queer women and women in sex work is an additional burden and adds complexity to the determinants of psychosocial health and wellbeing.

Practitioners and researchers would have to work together to re-orient societies, communities and women at the collective and individual levels to voice the importance of a woman's health and wellbeing throughout the life cycle, whether linked to her reproductive function or otherwise.

The global community of practitioners needs to come together in solidarity to recognise, write and create narratives, and lay the foundation for gender-equal societies where individuals are healthy and live a life devoid of bodily shame and despair.

\section{Notes:}

1 "Somatic symptom and related disorders are psychiatric conditions where patients experience distressing physical symptoms associated with abnormal thoughts, feelings, and behaviours in response to these symptoms. They may result from psychological stress that is unconsciously (without awareness) expressed somatically, though the underlying cause is not fully understood". (See: Conversion and somatic symptom disorders. BMJ Best Practice. 2021 Aug 13. https://bestpractice.bmj.com/topics/en-gb/989)

2 See: https://youtu.be/GQRwwlQ3a5c
References

1. National Institute of Mental Health and Neuro Sciences (NIMHANS) and MoHFW, Govt of India. National Mental Health Survey of India, 2015-16.. Bengaluru: NIM-HANS; 2016 [cited 2021 Jan 11]. Available from: http://www.indianmhs.nimhans.ac.in/Docs/Report2.pdf

2. World Health Organization. Regional Office for Europe. (2018). Mental health: fact sheet on Sustainable Development Goals (SDGs): health targets. WHO. Regional Of-fice for Europe; 2018[cited 2021 Jan11]. Available from: https://apps.who.int/iris/handle/ $10665 / 340847$

3. World Health Organization. Mental Health and Substance Use. Geneva: WHO. Date unknown [cited 2021 Jan 11]. Available from: https://www.who.int/teams/mental-health-and-substance-use/ gender-and-women-s-mental-health

4. PTI. Women's unpaid work worth 43 times the annual income of Apple, world's big-gest company: Report. Business Today.2019 Jan 21[cited 2021 Jan11]. Available from: www.businesstoday.in/wef2019/news/women-unpaid-work-worth-43-timesthe-annualincome-of-apple-world-biggest-company-report/story/ 311941.html

5. Leresche L. Defining gender disparities in pain management. Clin Orthop Relat Res. 2011 Jul;469(7):1871-7.

6. Hoffmann DE, Tarzian A J. The girl who cried pain: a bias against women in the treatment of pain. J Law Med Ethics. Spring 2001;29(1): 13-27. Doi: 10.1111/j.1748-720x.2001.tb00037.x.

7. Machtinger EL, Davis KB, Kimberg LS, Khanna N, Cuca YP, DawsonRose $C$, et al. From treatment to healing: Inquiry and response to recent and past trauma in adult health care. Women's Health Issues, 2019 Mar-Apr;29(2):97-102. Doi: https://doi.org/10.1016/j.whi. 2018.11.003

8. Heilman B, Barker G. Masculine norms and violence: Making the connections. Wash-ington, DC: Promundo-US; 2018.92 pgs.

9. Alangea DO, Addo-Lartey AA, Sikweyiya Y, Chirwa ED, Coker-Appiah $D$, Jewkes R, Adanu RMK. Prevalence and risk factors of intimate partner violence among women in four districts of the Central Region of Ghana: Baseline findings from a cluster randomised controlled trial. PLoS One. 2018 Jul 19; 13(7): e0200874. Doi: 10.1371/ journal.pone.0200874.

10. Eberhard-Gran M, Schei B, Eskild A. Somatic symptoms and diseases are more common in women exposed to violence. J Gen Intern Med. 2017 Dec; 22(12): 1668-73. Doi: 10.1007/s11606-007-0389-8.

11. Nayak M, Patel V, Bond J, Greenfield T. Partner alcohol use, violence and women's mental health: Population-based survey in India. $\mathrm{Br} J$ Psychiatry. 2010 Mar;196(3):192-9. Doi:10.1192/bjp.bp.109.068049.

12. United Nations Population Fund. Gender Equality. UNFPA; Date unknown [cited 2021 Sept 5 ], Available from: https:// www.unfpa.org/gender-equality

13. Boddy J. Wombs and Alien Spirits: Women, Men, and the Zar Cult in Northern Sudan. Madison, Wl: University of Wisconsin Press; 1989.

14. Cohen A. Site Visits. Updates on Global Mental and Social Health. 1997; 2:1.

15. Shodhini. Touch me, touch-me-not-Women, plants and healing. New Delhi: Kali for Women;1997.

16. Pachauri S, Gittelsohn J, Bentley M E, Pelto P J, Nag M, eds . Listening to women talk about their health: Issues and evidence from India. New Delhi:The Ford Foun-dation, Har-Anand Publications Pvt. Ltd; 2011. 